\title{
Evaluating rolling shear strength properties of cross-laminated timber by short-span bending tests and modified planar shear tests
}

\author{
Minghao $\mathbf{L i}^{1}$
}

Received: 8 February 2017/ Accepted: 22 April 2017/Published online: 13 May 2017

(C) The Japan Wood Research Society 2017

\begin{abstract}
This paper presents an experimental study on rolling shear (RS) strength properties of non-edge-glued cross-laminated timber (CLT) made out of New Zealand Radiata pine (Pinus radiata) structural timber. CLT specimens with 35 and $20 \mathrm{~mm}$ thick laminations were studied to evaluate the influence of lamination thickness on the RS strength of CLT. Short-span three-point bending tests were used to introduce high RS stresses in cross layers of CLT specimens and facilitate the RS failure mechanism. Modified planar shear tests from the conventional two-plate planar shear tests were also used to evaluate the RS strength properties. It was found that two test methods yielded comparable RS strength properties and the lamination thickness significantly affected RS strength of the CLT specimens. The test results also indicated that the recommended characteristic RS strength values of CLT products in Europe and Canada might be over conservative. Also, it might be more efficient to specify different RS strength values for CLT with different lamination thickness given the minimum width-to-depth ratio of laminations is satisfied.
\end{abstract}

Keywords Cross-laminated timber · Rolling shear · Bending tests · Planar shear tests $\cdot$ Radiata pine

Minghao Li

minghao.li@canterbury.ac.nz

1 Department of Civil and Natural Resources Engineering, University of Canterbury,

Private Bag 4800, Christchurch 8140, New Zealand

\section{Introduction}

Cross-laminated timber (CLT) is a composite panel product consisting of cross-wisely oriented layers of timber laminations normally bonded by adhesives. In recent years, CLT has gained global popularities among architects and engineers and has been applied in a large number of innovative timber buildings. CLT can be manufactured by timber laminations of different sizes. The lamination thickness can vary from 10 to $50 \mathrm{~mm}$ and the width can vary from 80 to $240 \mathrm{~mm}$. So far, design specifications of CLT buildings have not been officially incorporated into most of timber design codes. CLT building design has been largely driven by practitioners with mainly propriety design guidelines. There is still a strong need to develop a better understanding of properties of various CLT products, connection systems as well as the entire building systems for standardization and codification in future.

Rolling shear (RS) stress in wood is defined as the shear stress acting on the radial-tangential plane perpendicular to grain. RS strength of wood is very low compared with its longitudinal shear strength. In Eurocode 5 [1], characteristic RS strength of 1.0 MPa is often used for wood independent of strength classes. For CLT, due to the crosswise layup, high RS stresses may be induced in cross layers under high out-of-plane loads. For example, in a CLT floor supported by columns, high concentrated loads may cause critical RS zone in the supporting area; high bending loads on short-span CLT floors may also cause high RS stresses; or during construction, high RS stresses may occur in the vicinity of anchoring points for lifting. According to European Standard EN 16351:2013 [2], without testing, for CLT made out of common softwood species including Norway spruce (Picea abies), the characteristic RS strength may be taken as $1.1 \mathrm{MPa}$ for edge-glued products; for non- 
edge-glued CLT made out of laminations having a minimum width-to-depth ratio of 4 , the same characteristic RS strength 1.1 MPa can also be used. For other cases, $0.7 \mathrm{MPa}$ should be used.

A number of test standards can be used to study shear properties of wood and wood composites. Dumail et al. [3] followed the V-notched beam test method in ASTM D5379 [4] to study shear properties of Norway spruce as well as the relationship between wood density and shear modulus. Dahl and Malo [5] studied orthotropic shear properties of Norway spruce following the Arcan shear test, a similar test method to the $\mathrm{V}$-notched beam test except that the test specimens have a different shape to encourage shear failures. ASTM D2718 [6] provides Method A and Method B to evaluate the RS properties of plywood or other layered wood products. Method A is the planar shear test (often referred as the two-plate planar shear test) in which shear loads are applied by two metal plates glued onto the surfaces of the wood specimen. Biblis [7] used Method A to study RS modulus of sweetgum plywood. Method B is the five-point short-span bending test. Bradtmueller et al. [8, 9] used Method B to study shear properties of oriented strand board (OSB) and laminated veneer lumber (LVL). Other versions of short-span bending tests have also been used by researchers. For example, Norlin et al. [10] used threepoint bending tests to study RS and longitudinal shear strength properties of Douglas-fir veneers in a laminated veneer product. Yoshihara and Furushima [11] used asymmetric four-point bending tests to study the longitudinal shear strength of wood.

Research on RS properties of CLT has been also reported in recent years. Fellmoser and Blass [12] studied the influence of RS modulus on CLT plate stiffness using the bending vibration method. Mestek et al. [13] studied the influence of shear deformation of cross layers on load carrying capacity of CLT beams by conducting three-point bending tests. The influence of wood species, lay-ups, and clamping pressure for curing adhesives on RS strength was also investigated. Zhou et al. [14] used the two-plate planar shear tests and short-span bending tests to study RS strength and stiffness properties of CLT. Lam et al. [15] conducted torque loading tests on CLT shear blocks in which the cross layers were processed to have an annular cross section to facilitate RS failure mechanism. Li and Lam [16] studied RS damage accumulation and duration of load effect on CLT using low cycle fatigue bending tests and a stress-based damage accumulation model.

In this study, short-span three-point bending tests and modified planar shear tests were conducted to evaluate RS strength properties of non-edge-glued CLT made out of New Zealand Radiata pine (Pinus radiata) laminations. CLT specimens with different lamination thickness (35 and $20 \mathrm{~mm}$ ) were sampled and tested. The bending test used a short span to facilitate RS failure in the cross layers. Instead of using the two-plate planar shear test, a modified planar shear test was used following the similar test setup in AS/NZS 2269.1:2012 test standard for plywood [17]. The objective of this study was to experimentally evaluate RS strength properties of CLT made out of New Zealand Radiata pine structural timber; to investigate the effect of lamination thickness on RS strength of CLT; and to study the influence of different testing methods on the evaluation of RS strength properties.

\section{Materials and test methods}

\section{CLT specimens}

The specimens were sampled from six 3-layer CLT plates. Three plates had a 20/20/20 layup and the other three had a $35 / 35 / 35$ layup, as shown in Fig. 1. The plate size was about $2 \mathrm{~m} \times 2.7 \mathrm{~m}$. For simplicity, CLT35 refers to the specimens with $35 \mathrm{~mm}$ thick laminations and CLT20 refers to the specimens with $20 \mathrm{~mm}$ thick laminations. The specimens were manufactured from $35 \mathrm{~mm} \times 165 \mathrm{~mm}$ and $20 \mathrm{~mm} \times 195 \mathrm{~mm}$ Radiata pine structural grade timbers, respectively. One-component Purbond polyurethane adhesive was used to bond the timber layers under vacuum pressing without edge-gluing.

Table 1 shows the CLT configurations including lamination grades, thickness, and dimensions of specimens cut for the bending testing and the modified planar shear testing. The outer layers (or face layers) consisted of SG8 boards and the inner layers (also the cross layers for 3-layer CLT) consisted of SG6 boards. In New Zealand, SG8 Radiata pine timber is the most common structural grade timber widely used in timber construction. As given in Table 2, the specified average modulus of elasticity (MOE) values of SG8 timber and SG6 timber are $8 \mathrm{GPa}$ (or $8000 \mathrm{MPa}$ ) and $6 \mathrm{GPa}$ (or $6000 \mathrm{MPa}$ ), respectively. The average density of all the CLT35 specimens was $455 \mathrm{~kg} / \mathrm{m}^{3}$, with coefficient of variation (COV) of 0.066 . The average density of all the CLT20 specimens was $446 \mathrm{~kg} / \mathrm{m}^{3}$, with COV of 0.045 .

\section{Short-span bending tests}

10 bending specimens were sampled from each plate. Therefore, for each type of CLT, a total of 30 bending specimens were tested. Three-point bending tests with a span-to-depth ratio of six were adopted, as shown in Fig. 2. Sawing patterns of the laminations were not considered because laminations with mixed sawing patterns are typically used in the actual manufacturing process. Gap locations in cross layers were random and not considered. Gap sizes in cross layers were measured between 0.2 and $2 \mathrm{~mm}$. 


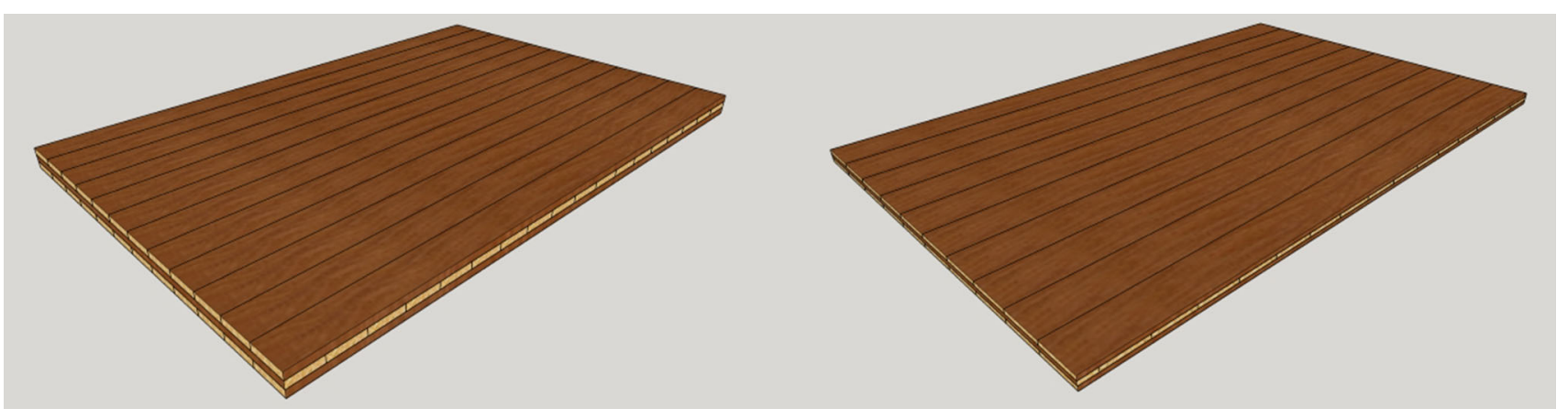

Fig. 1 CLT plates with 35/35/35 layup and 20/20/20 layup

Table 1 Configuration of cross-laminated timber (CLT) specimens

\begin{tabular}{lllll}
\hline Type & Lamination grade & Lamination thickness $(\mathrm{mm})$ & \multicolumn{2}{l}{ Dimension of specimens $(\mathrm{mm} \times \mathrm{mm} \times \mathrm{mm})$} \\
\cline { 4 - 5 } & & & Bending & Planar shear \\
\hline CLT20 & SG8/SG6/SG8 & $20 / 20 / 20$ & $420 \times 50 \times 60$ & $165 \times 50 \times 60$ \\
CLT35 & SG8/SG6/SG8 & $35 / 35 / 35$ & $735 \times 50 \times 105$ & $165 \times 50 \times 105$ \\
\hline
\end{tabular}

CLT20 refers to the cross-laminated timber specimens with $20 \mathrm{~mm}$ thick laminations; CLT35 refers to the cross-laminated timber specimens with $35 \mathrm{~mm}$ thick laminations; SG8 refers to stress grade 8 structural timber; and SG6 refers to stress grade 6 structural timber
Table 2 Input stiffness properties of cross-laminated timber (CLT) laminations

\begin{tabular}{lllll}
\hline Lamination grade & $E_{\|}(\mathrm{MPa})$ & $E_{\perp}(\mathrm{MPa})$ & $G_{0}(\mathrm{MPa})$ & $G_{\mathrm{RS}}(\mathrm{MPa})$ \\
\hline SG8 & 8000 & 267 & 533 & 53 \\
SG6 & 6000 & 200 & 400 & 40 \\
\hline
\end{tabular}

SG8 refers to stress grade 8 structural timber; SG6 refers to stress grade 6 structural timber; $E_{\|}$refers to $E$ value parallel to grain; $E_{\perp}$ refers to $E$ value perpendicular to grain; $G_{0}$ refers to longitudinal shear modulus and $G_{\mathrm{RS}}$ refers to rolling shear modulus

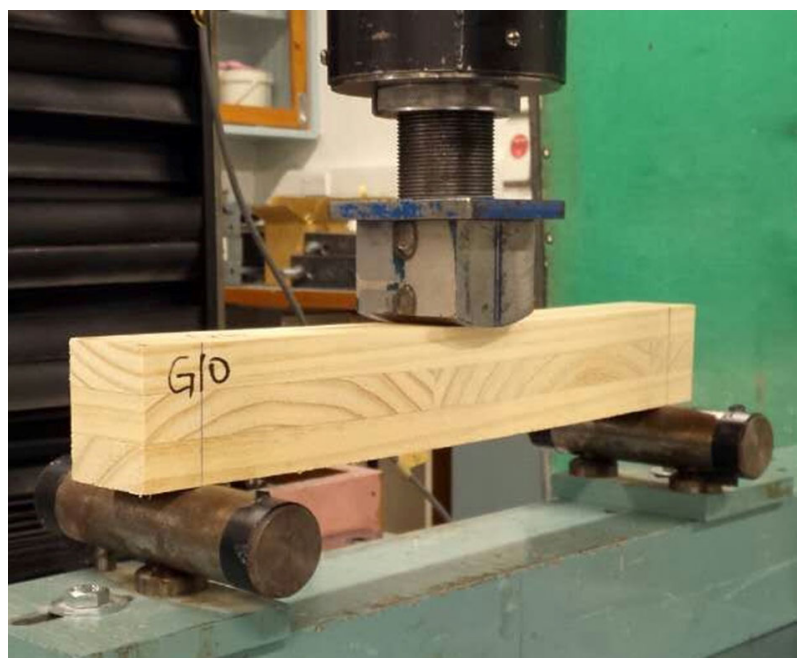

Fig. 2 Short-span bending test setup

For the CLT35 specimens, average moisture content was measured to be $10.9 \%$, with COV of 0.119 . For the CLT20 specimens, it was $11.6 \%$, with COV of 0.097 . The loading rate was $1 \mathrm{~mm} / \mathrm{min}$ for the CLT20 specimens and $2 \mathrm{~mm} /$ min for the CLT35 specimens so that the time to failure for each specimen was about 4-5 min.

\section{Modified planar shear tests}

Similarly, 10 planar shear specimens were sampled from each plate. For each type of CLT, a total of 30 specimens were tested using the modified planar shear tests. The length and width of the specimens were 165 and $50 \mathrm{~mm}$, respectively. The thickness was equal to the CLT plate thickness, i.e., $60 \mathrm{~mm}$ for the CLT20 specimens and $105 \mathrm{~mm}$ for the CLT35 specimens. The specimens were prepared so that the face layers and the cross layers did not contain any gaps. For the CLT20 specimens, the average moisture content was $11.4 \%$, with $\mathrm{COV}$ of 0.122 . For the CLT35 specimens, the average moisture content was $11.5 \%$, with COV of 0.099 .

As shown in Fig. 3, the test setup was similar to that used in AS/NZS 2269.1:2012 standard [17]. The original test jig in the standard consists of 4 steel plates in two pairs which are connected to plywood with small bolted connections. In this study, adjustments of the test jigs were made to accommodate for the dimensions of the specimens and higher load level. The length of the steel plates was increased and screwed connections instead of small bolted connections were used to transfer loads between the steel plates and the wood specimen. Each pair of the plates was 

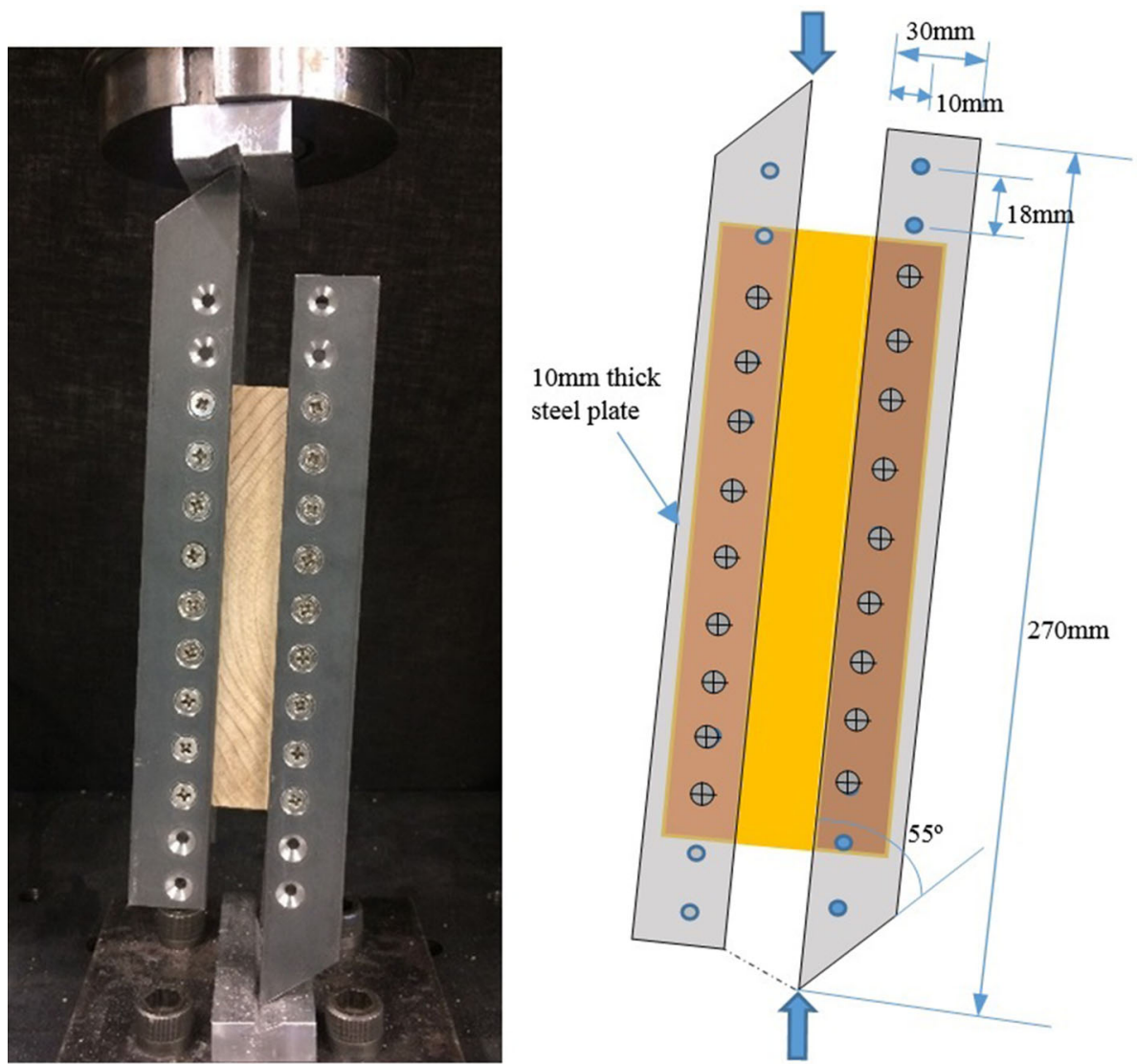
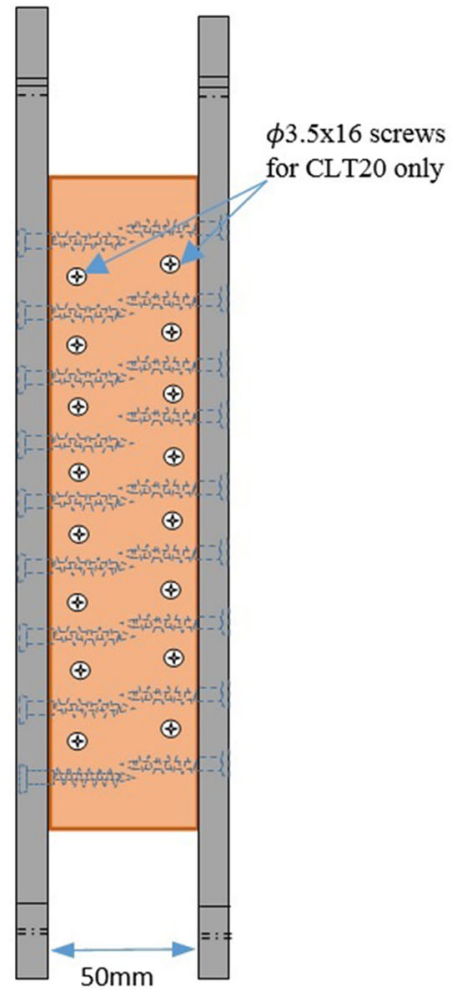
for CLT20 only
Fig. 3 Modified planar shear test setup

connected with one face layer of the specimen via two rows of $\phi 4.7 \mathrm{~mm} \times 32 \mathrm{~mm}$ stainless screws installed on opposite sides. Shear loads were applied onto one pair of the steel plates by the loading machine, transferred to one face layer by those screwed connections, and then transferred onto the cross layer via glue lines between the face layer and the cross layer. Due to relatively thin laminations used in the CLT20 specimens, $\phi 3.5 \mathrm{~mm} \times 16 \mathrm{~mm}$ steel wood screws were additionally driven into the face layers between the stainless screws along the perpendicular to grain direction to eliminate wood splitting caused by the screwed connections under high shear loads. The loading rate was $1 \mathrm{~mm} / \mathrm{min}$ for both types of specimens. The time to failure for each specimen was about 4-8 min.

\section{Test results}

The CLT20 and CLT35 bending specimens typically failed in RS, as shown in Fig. 4. Shear cracks were initiated in the cross layers with an inclined angle mostly $40^{\circ}-50^{\circ}$ with respect to the beam axis and some of them were further propagated to the glue lines between the layers. Such a failure mode was very brittle. For the CLT20 specimens, 2 out of 30 specimens also experienced secondary tensile failure at bottom edge at the final loading stage. For the CLT30 specimens, 6 out of 30 specimens experienced the tensile failures at the bottom edge at the final loading stage.

Classic beam theories with the assumption of parabolic shear stress distribution along beam depth are commonly used to calculate shear strength of wood products, such as the RS strength calculation for plywood in ASTM D2718 standard [6]. However, such an assumption of parabolic shear stress distribution is not valid for CLT because the cross layers often have much lower $E$ and $G$ values than the longitudinal layers. In this study, shear analogy method developed by Kreuzinger [18] for composite beams was used. This method takes into account shear deformations in cross layers. The stiffness values of the laminations used for the RS strength calculations are shown in Table 2. The stiffness relationships $E_{\perp} \approx E_{\|} / 30, G_{0} \approx E_{\|} / 15$, and $G_{\mathrm{RS}} \approx G_{0} / 10$ were assumed following the CLT handbook [19].

Figure 5 shows the cumulative distributions of the calculated RS strength values of the bending specimens. The RS failure load was taken as the peak load recorded during the test because the secondary tensile failure occurred mostly at the post-peak stage. The CLT20 specimens with $20 \mathrm{~mm}$ thick laminations had significantly higher RS strength than the CLT35 specimens with $35 \mathrm{~mm}$ thick 


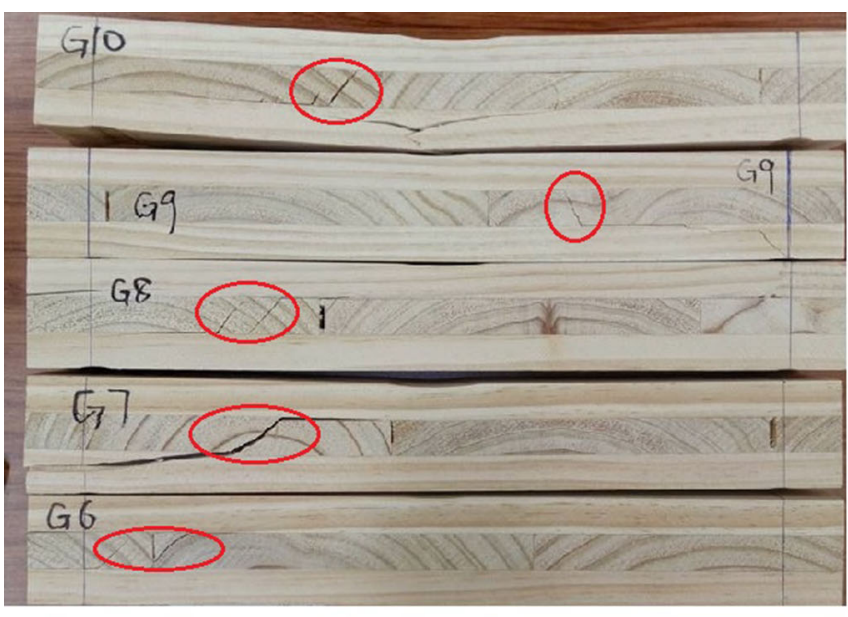

CLT20 bending specimens

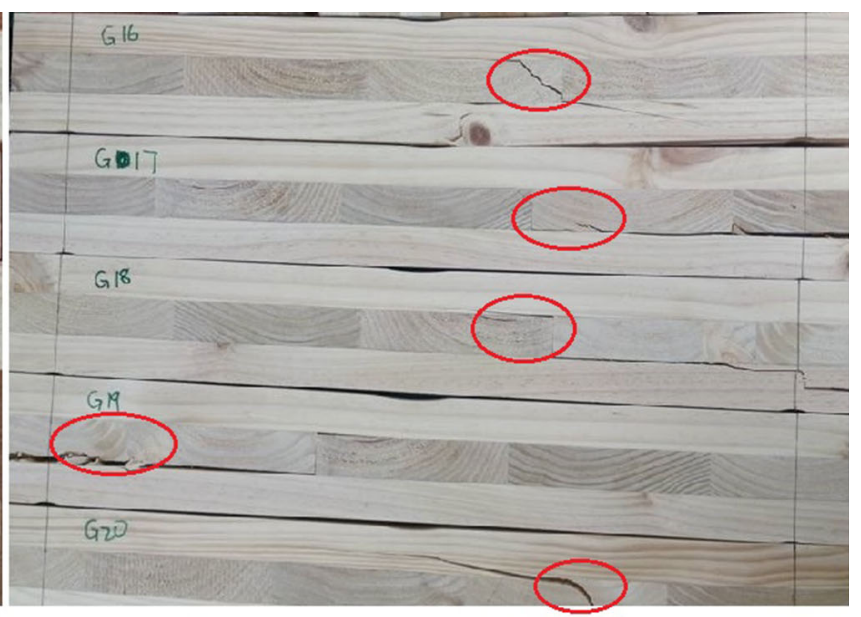

CLT35 bending specimens

Fig. 4 Typical rolling shear failure modes observed in the bending specimens

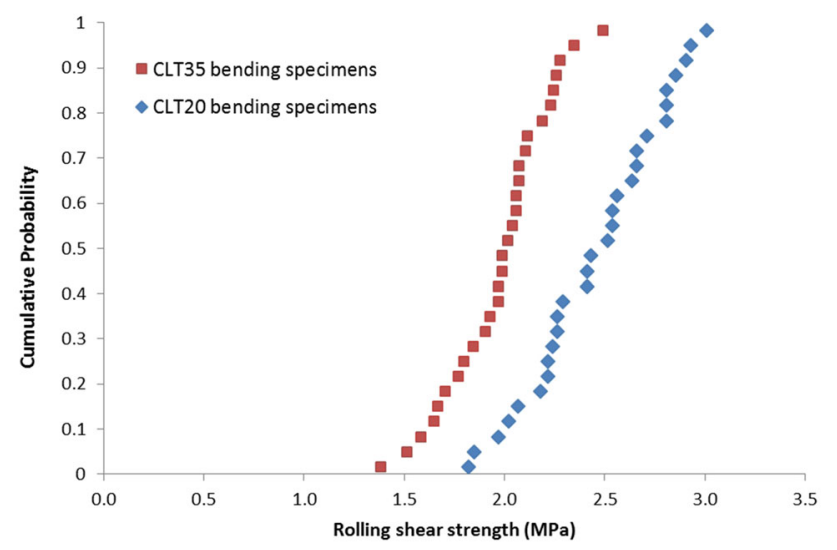

Fig. 5 Cumulative distribution of RS strength of the bending specimens

laminations. For the CLT35 specimens, the average RS strength was $1.97 \mathrm{MPa}$ with COV of 0.131 . Its characteristic RS strength was calculated as $1.45 \mathrm{MPa}$ following Method 3 (non-parametric) in AS/NZS 4063.2:2010 standard [20] which stipulates common methods to determine characteristic values for structural timber. The average RS strength of the CLT20 specimens was $2.45 \mathrm{MPa}$ with COV of 0.135 . Its characteristic RS strength was $1.77 \mathrm{MPa}$.

Figure 6 shows the typical RS failure modes observed in the specimens tested by the modified planar shear tests. Similar to the bending specimens, shear cracks with inclined angles were observed in the cross layers and the specimens failed abruptly when one or multiple shear cracks were developed through the thickness of the cross layers and propagated to the glue lines.

The RS strength was simply calculated by dividing the failure load by loaded shear area $(165 \mathrm{~mm} \times 50 \mathrm{~mm})$. Figure 7 shows the cumulative distributions of the calculated RS strength of the planar shear specimens. It can be seen that the CLT20 specimens also had significantly higher RS strength than the CLT35 specimens. The average RS strength of the CLT 35 specimens was $1.99 \mathrm{MPa}$ with $\mathrm{COV}$ of 0.122 and the characteristic strength was $1.49 \mathrm{MPa}$; the average RS strength of the CLT20 specimens was $2.33 \mathrm{MPa}$ with COV of 0.127 and the characteristic RS strength was $1.84 \mathrm{MPa}$.

Table 3 lists the summary of all the test results in terms of average RS strength, COV and the characteristic strength values. Combining both sets of the test results, the average RS strength of the CLT20 specimens was $21 \%$ higher than that of the CLT35 specimens. Also, the characteristic RS strength of the CLT20 specimens was $23 \%$ higher.

\section{Discussions and conclusions}

This study experimentally evaluated RS strength properties of Radiata pine CLT products made out of $35 \mathrm{~mm}$ thick laminations and $20 \mathrm{~mm}$ thick laminations using short-span bending tests and modified planar shear tests. The test results showed that the characteristic RS strength of the CLT specimens was significantly higher than the recommended values of most of the softwood CLT products from Europe and Canada. For example, European Standard EN 16351:2013 [2] suggests that 1.1 MPa be used for edgeglued CLT products made out of common European softwood species without testing; In Canada, a much lower value of $0.5 \mathrm{MPa}$ is recommended for CLT products made out of Spruce-Pine-Fir species group.

The short-span bending tests and the modified planar shear tests yielded comparable RS strength properties (on an average, 1.97 vs. $1.99 \mathrm{MPa}$ for the CLT35 specimens; 2.45 vs. $2.33 \mathrm{MPa}$ for the CLT20 specimens). In the 
Fig. 6 Typical RS failure modes observed in the planar shear specimens

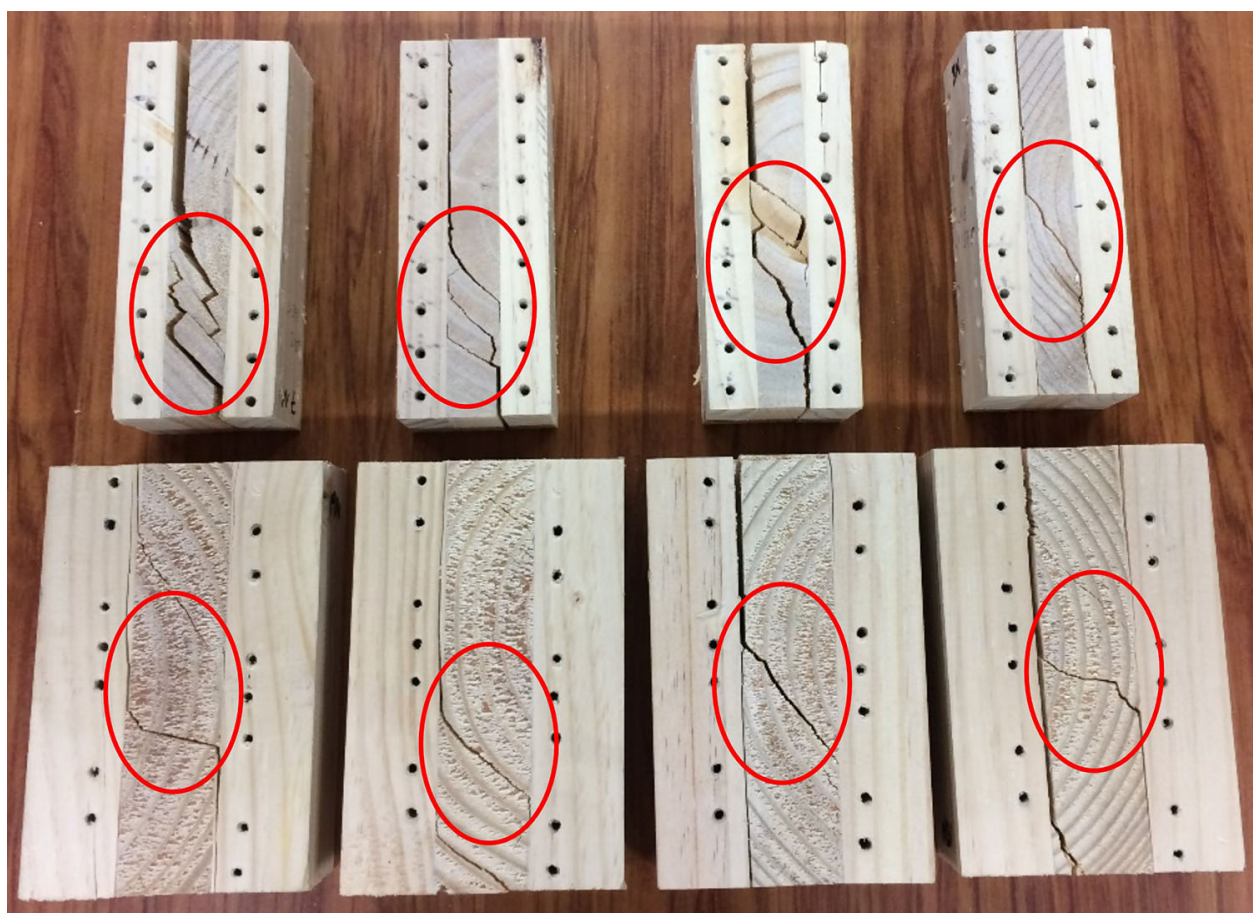

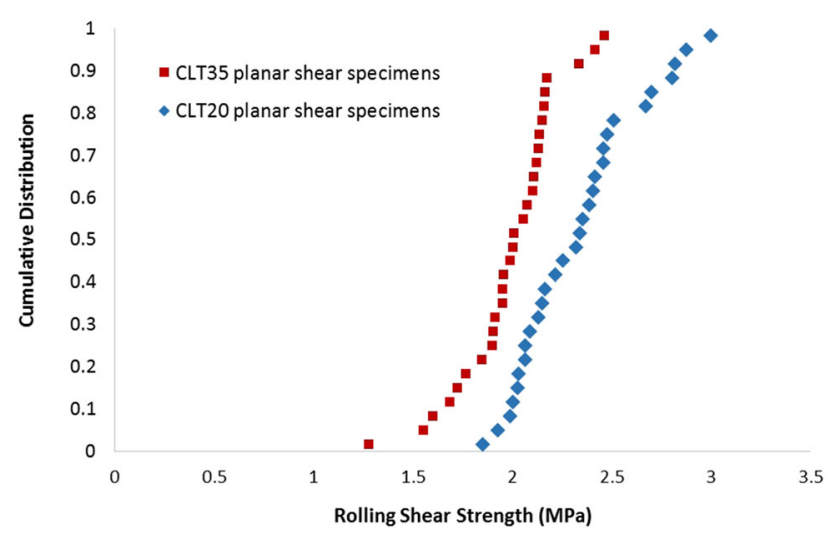

Fig. 7 Cumulative distribution of RS strength of the planar shear specimens

bending tests, due to the short span, relatively high compressive stresses perpendicular to grain may be introduced in cross layers thus affecting the evaluation of RS strength in cross layers. In the modified planar shear tests, the specimens were loaded in a relatively "pure shear" mode and the minor compressive stress introduced by the small angle between the loading direction and the specimen major direction may not significantly affect the RS evaluation. However, the specimens tested under these two methods had different dimensions and different volumes of wood in cross layers that were loaded in RS, which could affect the RS strength evaluation as well.

Lamination thickness was found to significantly affect the RS strength properties of CLT. Combining both sets of the test results, the CLT35 specimens had the average RS strength of $1.98 \mathrm{MPa}$ and the characteristic RS strength of 1.47 MPa and the CLT20 specimens had the average RS strength of $2.39 \mathrm{MPa}$ and the characteristic RS strength of 1.81 MPa. Such a relationship between the lamination thickness and the RS strength can be also explained by size effect on RS strength of wood. The CLT35 specimens had much larger volume of wood loaded under RS stresses and the probability of having more critical strength-reducing deflects is higher than that the CLT20 specimens.

Table 3 Statistics of rolling shear (RS) strength properties

\begin{tabular}{|c|c|c|c|c|c|c|}
\hline \multirow[t]{2}{*}{ Type } & \multicolumn{3}{|l|}{ Bending tests } & \multicolumn{3}{|c|}{ Planar shear tests } \\
\hline & Mean (MPa) & $\mathrm{COV}$ & Characteristic value (MPa) & Mean (MPa) & $\mathrm{COV}$ & Characteristic value (MPa) \\
\hline CLT35 & 1.97 & 0.131 & 1.45 & 1.99 & 0.122 & 1.49 \\
\hline CLT20 & 2.45 & 0.135 & 1.77 & 2.33 & 0.127 & 1.84 \\
\hline
\end{tabular}

CLT35 refers to the cross-laminated timber specimens with $35 \mathrm{~mm}$ thick laminations; CLT20 refers to the cross-laminated timber specimens with $20 \mathrm{~mm}$ thick laminations; and COV refers to coefficient of variation 
Besides the lamination thickness effect on RS strength, the width-to-thickness of laminations is also believed to affect RS strength evaluations. European Standard EN 16351:2013 [2], thus recommends the minimum width-tothickness ratio of 4 to use higher RS characteristic strength of 1.1 MPa. Similarly, in Canada, the minimum width-todepth ratio of 3.5 is recommended [19]. In this study, the width-to-depth ratios of the laminations in the CLT specimens all exceeded 4. Further research is required to study how the width-to-thickness ratio affects the RS strength of CLT in a quantitative manner. Given minimum width-todepth ratio is satisfied, it seems more rational to provide different RS strength properties for CLT products consisting of different lamination thickness.

Acknowledgements The author would like to thank Mr. Alan Poynter from Model Structure Laboratory at University of Canterbury for providing technical assistance and $\mathrm{Mr}$. Tianxiao $\mathrm{Hu}$, Mr. Chang Cheng, Mr. Thomas Keall-Grant and Mr. Cameron Nixon for conducting experimental tests as undergraduate research projects.

\section{References}

1. Eurocode 5 (2004) Design of timber structures. Part 1-1: general-common rules and rules for buildings EN 1995-1-1. CEN, Brussels

2. BS EN 16351 (2015) Timber structures-cross-laminated timber-requirements. BSI Standards Publication, London

3. Dumail JF, Olofsson K, Salmen L (2000) An analysis of RS of spruce wood by the Iosipescu method. Holzforschung 54(4):420-426

4. ASTM D5379/D5379M (2005) Standard test method for shear properties of composite materials by the V-notched beam method. ASTM International, USA

5. Dahl KB, Malo KA (2009) Linear shear properties of spruce softwood. Wood Sci Technol 43:499-525
6. ASTM D2718-00 (2006) Standard test methods for structural plates in planar shear (RS). ASTM International, USA

7. Biblis EJ (2000) RS modulus of sweetgum plywood and unidirectionally laminated veneer. Wood Fiber Sci 32(1):2-6

8. Bradtmueller J, Hunt M, Fridley K, McCabe G (1997) Mechanical properties of OSB via the five-point test. For Prod J 47(9):70-77

9. Bradtmueller J, Hunt M, Shook S (1998) Mechanical properties of laminated veneer lumber via five-point bending test. J Test Eval 26(2):132-137

10. Norlin LP, Norlin CM, Lam F (1999) Shear behaviour of laminated Douglas fir veneer. Wood Sci Technol 33:199-208

11. Yoshihara H, Furushima $\mathrm{T}$ (2003) Shear strengths of wood measured by various short beam shear test methods. Wood Sci Technol 37:189-197

12. Fellmoser P, Blass HJ (2004) Influence of RS modulus on strength and stiffness of structural bonded timber elements. CIBW18/37-6-5 Edinburgh, UK

13. Mestek P, Kreuzinger H, Winter S (2008) Design of cross-laminated timber (CLT). In: Proceedings of WCTE 2008, Miyazaki, Japan

14. Zhou QY, Gong M, Chui YH, Mohammad M (2014) Measurement of rolling shear modulus and strength of cross-laminated timber using bending and two-plate shear tests. Wood Fiber Sci 46(2):259-269

15. Lam F, Li Y, Li M (2016) Torque loading tests on the rolling shear strength of cross-laminated timber. J Wood Sci 62:407-415

16. Li Y, Lam F (2016) Low cycle fatigue tests and damage accumulation models on the rolling shear strength of cross-laminated timber. J Wood Sci 62:251-262

17. Australian/New Zealand Standard 2269.1 (2012) Plywoodstructural part 1: determination of structural properties-test methods. Standards New Zealand, Wellington

18. Kreuzinger H (1999) Flaechentragwerke-platten, scheiben und schalen-ein Berechnungsmodell fuer gaengige Statikprogramme (in German). Bauen mit Holz. 01/1999, S:34-39

19. CLT Handbook-Canadian Edition (2011) Chapter 2 Manufacturing. FPInnovations, Vancouver, pp II-10

20. Australian/New Zealand Standard 4063.2 (2010) Characteristic of structural timber part 2: determination of characteristic values. Standards New Zealand, Wellington 